\title{
Strength and liquefaction assessment of tailings
}

\author{
M.J. Dillon ATC Williams, Australia \\ H.J. Wardlaw ATC Williams, Australia
}

\begin{abstract}
Historically, in situ testing of tailings has been primarily based on drilling techniques with the recovery of tube samples, coupled with standard penetration test (SPT), shear vane testing and laboratory test work used to assess the tailings properties. These techniques have limitations. In more recent time, the uses of cone penetrometer testing (CPTu) and associated analytical techniques have lead to an improved understanding of tailings in situ properties.

A combination of both drilling and CPTu techniques is considered appropriate for identifying the key engineering properties of tailings. The results of the investigation can then be used in both stability and seismic liquefaction analyses.
\end{abstract}

Results from the investigation of two different tailing deposition regimes are presented together with their strength and liquefaction assessments.

\section{Introduction}

The stability of the tailings and associated embankments is dependent upon the strength properties of the tailings and the stress conditions under which the tailings are found. The stress conditions are dependent on the density, degree of saturation, plasticity and permeability of the tailings. The stress conditions are also dependent on external loading such as changes in pore pressures due to changes in pond level, construction loads on the tailings, high rates of rise of the tailings and seismic loads.

Seismic loads, the cyclic loading effects of an earthquake, may cause deformation of the tailings and in extreme cases the liquefaction of the tailings with a temporary loss of strength of the tailings. Seismic liquefaction refers to a sudden loss in stiffness and strength of soil as a result of the earthquake.

Analysis for assessing the liquefaction potential of a fine-grained soil or tailings requires the derivation of soil parameters. These parameters can be derived from empirical relationships but more commonly are obtained through a combination of field investigations and laboratory test work. Cone penetrometer testing $(\mathrm{CPTu})$ together with calibration against geotechnical borehole testing is the method generally adopted.

This paper presents a brief discussion on investigation techniques, followed by a comparison of the results of the investigation of two different types of tailings disposal schemes. One is a down valley thickened tailings discharge tailings storage facility (TSF), and the other a perimeter, segregating slurry discharge TSF, for which centreline raising was used.

\section{Investigation techniques}

\subsection{Drilling and laboratory testing}

The use of drilling techniques in tailings can only provide part of the overall picture. Generally the preferred drilling methods are the use of hollow auger or wash bore techniques, although there are other methods available. In situ testing and sampling is carried out as intervals and can include shear vane, standard penetration tests (SPT), tube sampling (where the tailings can be recovered intact) and slurry sampling where the tailings cannot be recovered within an open tube.

It is considered that SPT testing within tailings is an ineffective test method in soft deposits, as generally the drill string will fall under the self-weight of the SPT hammer. However, it is useful method of retrieving disturbed samples. 
To obtain an indication of the phreatic surface within the tailings requires the installation of a standpipe piezometer. However, this only provides an estimate of the standing water level rather than an indication of the pore pressures within the tailings.

The issue with this approach is that information is only obtained at discrete depths within the tailings profile. It is very difficult to assess the material between testing intervals by use of drilling rate variations, due to the generally soft nature of tailings. This said, tailings crustal layers could sometimes be identified.

Laboratory testing of samples recovered during a drilling investigation typically includes classification test work such as moisture content, particle size distribution, plasticity, particle specific gravity, and in situ density tests, and possibly strength testing in the form of triaxial tests on tube samples.

\subsection{Cone penetrometer testing}

The first use of the $\mathrm{CPTu}$ with pore pressure measurement is for stratigraphic logging and preliminary evaluation of the geotechnical parameters within the tailings profile.

$\mathrm{CPTu}$ is generally undertaken from a self-contained unit, such as a probe truck or a drilling rig or some other reaction force, which can be used to advance the probe.

The data obtained from the CPTu can be used for design purposes where the material is known to be uniform and where the material properties are locally verified and correlated. By nature, tailings deposits are nonuniform either on account of segregation, variations in depositional mode, or variations in the degree of wetting and drying, As such, used in isolation, this method only provides stratigraphic data on the tailings profile and can only be used as a preliminary screening tool.

In addition to recording penetration data, dissipation tests can be carried out, wherein advancement of the probe is halted and the induced pore pressure is allowed to dissipate. This provides an estimate of the pore pressures within the tailings. By performing tests at various depths an understanding of either excess pore pressures as is the case in under-consolidated tailings or drainage conditions within the tailings can be reached.

An alternative to traditional drilling methods for recovering samples is to perform a dummy CPT adjacent to the $\mathrm{CPTu}$ and sample the tailings using the Mostap or similar sampling technique, which is similar in nature to a fixed-piston sampler.

\subsection{The combined approach}

The combined approach utilises both drilling/sampling and CPTu methods. As tailings dams are generally located away from major population areas, it is sometimes cost prohibitive to mobilise both a drilling rig and a dedicated probe truck. The alternative is to mobilise a drill rig and use this to push a portable CPTu probe. It is recommended that the first phase of the investigation should comprise of the CPTu probe, followed by the drilling and sampling as the second phase, then the laboratory test work. The CPTu probe provides the stratigraphic profile of the tailings. From this, in situ testing and sampling can be targeted to critical depths within the profile. Standpipe piezometers may also be installed using the drill rig if necessary.

Laboratory testing of the recovered samples is then used to confirm and validate the CPTu correlations.

The CPTu results are analysed to assess the material type and apparent fines content using the soil classification method developed by Robertson (1990). The apparent fines content can then be compared to the fines content of samples from known depths. This provides a good estimate of the validity of the results as this method relies on the tip resistance $\left(\mathrm{q}_{\mathrm{c}}\right)$ from the CPTu testing. If the comparison between the apparent fines content derived from $\mathrm{q}_{\mathrm{c}}$ and the laboratory test results differ, this could be an indication that the CPT cone is not in calibration.

The undrained shear strength estimated from the CPTu data can also be compared to field shear vane results using the method presented by Youd et al. (2001). It has been the authors' experience that shear vane results are generally higher than the undrained shear strength estimated using the Robertson method. For the purpose of analysis the authors adopt the lower bound undrained shear strength from the CPTu data. 
The post liquefaction, or residual strength can be estimated from the CPTu data using the method presented by Olson and Stark (2002).

\section{$3 \quad$ Assessment of seismic liquefaction}

\subsection{What is seismic liquefaction?}

Seismic liquefaction is the process whereby the strength of a soil, or tailings is reduced by the application of an earthquake load to the undrained residual strength (or steady state undrained strength). The mechanism is a sudden loss in stiffness and strength of soil, as a result of the response of the soil to shearing due to the cyclic loading effects of an earthquake. This loss in strength arises from a reasonably loose material initially being unable to contract or dilate as a result of saturation, and then to contract under cyclic loading of an earthquake coupled with an inability to drain in the short time frame of seismic loading. This leads to a rise in porewater pressure and a resulting decrease in effective stress and hence strength of the tailings.

In addition, during shearing, there is a brief moment during the re-arrangement of the particles when they are, in a sense, "floating" (liquefaction). The momentary reduction in particle-to-particle contact leads to a substantial loss of strength (brittleness) and the soil liquefies. It is important to note that liquefaction does not necessarily imply that the liquefied soil has zero shear strength; it has reduced shear strength.

The susceptibility of a tailings deposit to liquefaction is to some extent dependent upon plasticity and particle size distribution. Three factors must be present together before liquefaction can take place:

1. Loose, cohesionless or low plasticity material (typically fine sand/silt, but also silts and silty clays). Determination of density profiles is thus considered an important parameter for any tailings investigation.

2. Saturation; dictated by the location of the water table. Dry soils cannot liquefy. Conversely, because tailings deposits are placed relatively quickly, they are often under-consolidated and thus can have excess pore pressures. Excess pore pressures reduce the effective strength of the deposit and can exacerbate the risk of liquefaction.

3. Shaking of sufficient magnitude and duration; seismic activity, like rainfall, is more probable at some locations than others and thus it is described in items of probability and recurrence interval. Ideally a site-specific seismic risk assessment should be completed for high-risk dams.

The post liquefaction behaviour of a tailings storage depends on the ratio of available strength to the stresses that are acting. A flow slide is defined as slope instability that results when a soil liquefies, and the disturbing forces exceed the strength. If this strength is sufficient, it will prevent a flow slide from occurring, but may still result in excessive displacements. In addition, significant settlements may occur because of dissipation of excess porewater pressures during and after the period of strong ground shaking. The consequences of this type of behaviour are dependent on the details of the storage in question.

It should also be noted that liquefaction could also occur, under certain circumstances, under static conditions. Static liquefaction can be caused by an increase in pore pressure due to rapid loading or loss of toe restraint. For example on a down valley storage a slippage of the tailings beach has been known to occur adjacent to the supernatant pond.

\subsection{Soils susceptible to liquefaction}

There have been numerous hypotheses as to which soil types are susceptible to liquefaction. It seems to be generally agreed that two of the main criteria are the particle size of the soil or tailings and the plasticity of the material. Work by Ishihara et al. (1980) and Seed et al. (2003) provide good estimates of the range of materials susceptible to liquefaction.

Figure 1 illustrates particle size distributions for soils typically associated with liquefaction and the envelope of tailings considered susceptible to liquefaction (Ishihara et al., 1980). It is suggested that the difference between natural soils and tailings is because the tailings have been milled rather than having undergone a natural process. 


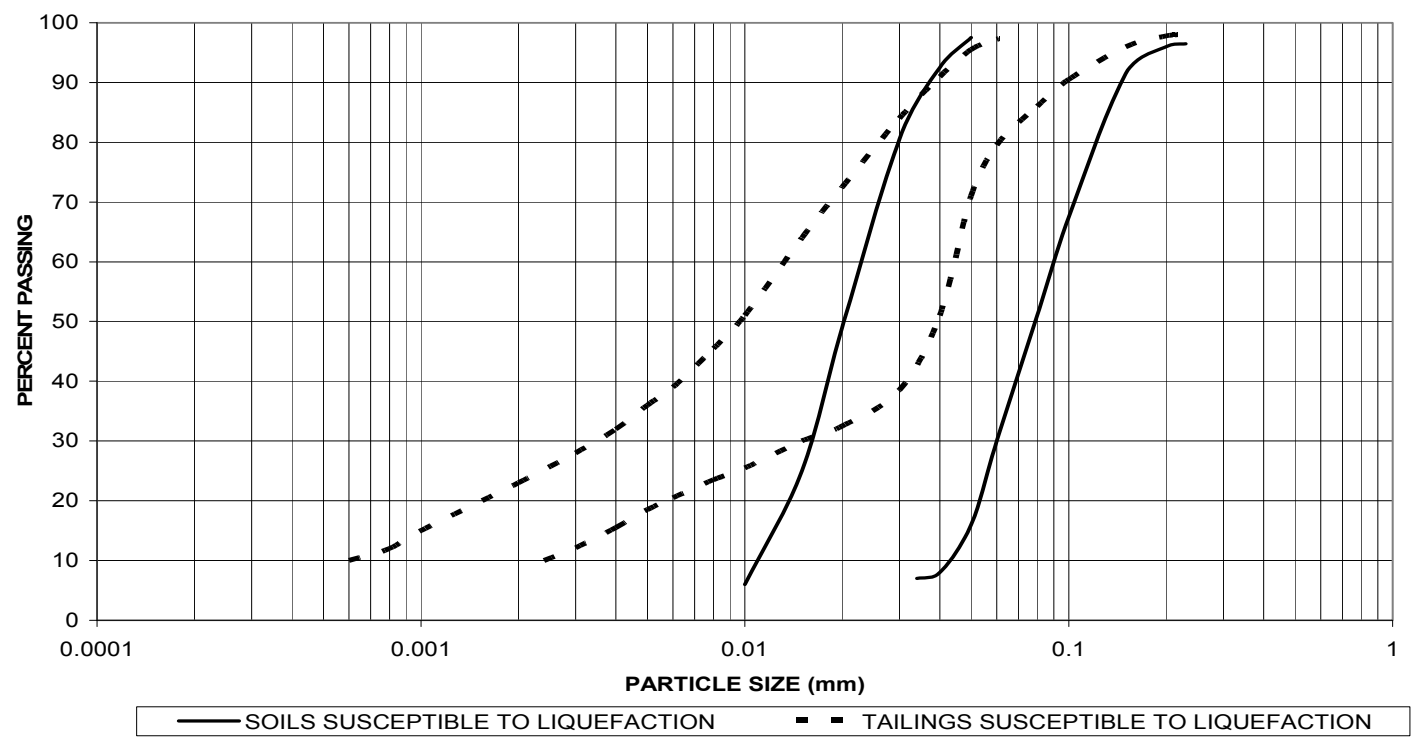

Figure 1 Soils and tailings subject to liquefaction

Figure 2 illustrates the influence of plasticity on potential liquefaction of a soil. As can be seen from the chart, low plasticity clays and silts are considered to be susceptible to liquefaction (Seed et al., 2003).

This should not be taken to imply that high plasticity materials will not have low strength, and will not experience significant deformations during shaking. The difference is that there will be no strength reduction.

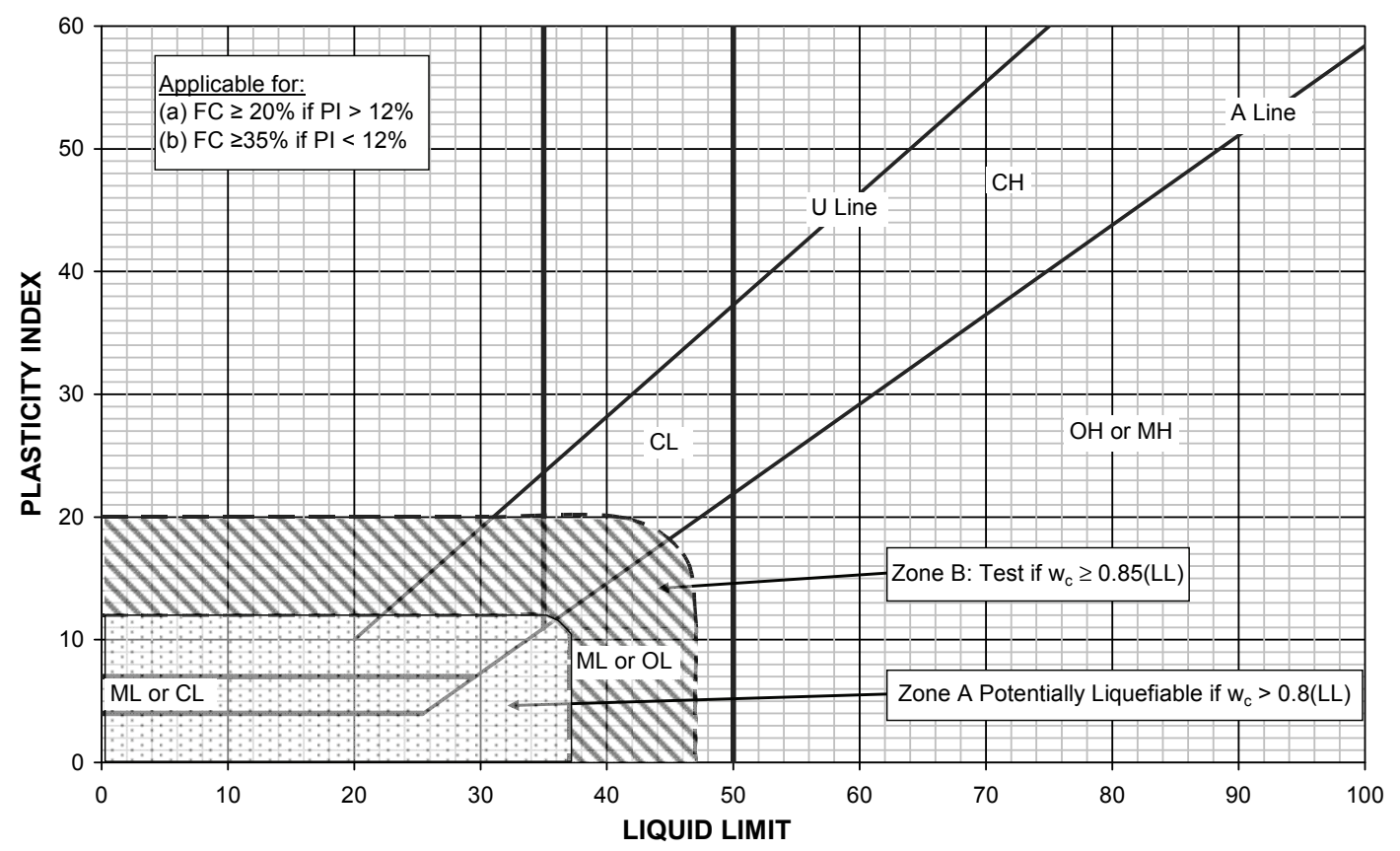

Figure 2 Plasticity chart and tailings liquefaction potential

\subsection{General method used for strength and liquefaction assessment of tailings}

For the assessment of tailings strength and liquefaction potential of tailings the authors have adopted a procedure which follows the methods of Robertson (1990), Lunne et al. (2001), Youd et al. (2001) methods and Olson and Stark (2002). 


\subsubsection{Classification}

The Robertson (1990) method is used to determine the soil type and apparent fines content of the tailings. These results are then compared to laboratory test results. It has been found that there is generally a good correlation between the laboratory test results and the apparent fines content.

\subsubsection{Interpreted strengths}

An estimation of the undrained shear strength of the tailings is obtained from correlations outlined by Lunne et al. (2001) and is based on the total cone resistance from CPTu data.

The shear strength ratio of the tailings relates the undrained shear strength to the effective overburden stress through Equation (1).

$$
k=S_{u} / \sigma_{v o}{ }^{\prime}
$$

where:

$k=$ the shear strength ratio.

$s_{u} \quad=\quad$ undrained shear strength (peak or residual).

$\sigma_{v o}{ }^{\prime}=$ effective overburden stress. The effective stress of the tailings material is calculated based on density and recorded water level or water levels from CPTu dissipation test results.

\subsubsection{Liquefaction assessment}

The purpose of liquefaction (risk) assessment is to evaluate whether soil or tailings will liquefy under a given magnitude of earthquake shaking. The Youd et al. (2001) method involves the determination of the cyclic stress ratio (CSR) and the cyclic resistance ratio $\left(\mathrm{CRR}_{7.5}\right)$ normalised to a Magnitude 7.5 event.

The CSR is defined in Equation (2).

$$
C S R=0.65 \times\left(\frac{a_{\max }}{g}\right) \times\left(\frac{\sigma_{v o}}{\sigma_{v o}^{\prime}}\right) \times r_{d}
$$

where:

$$
\begin{array}{lll}
a_{\max } & = & \begin{array}{l}
\text { peak horizontal acceleration at ground surface operating base earthquake or maximum } \\
\text { design earthquake (OBE or MDE). }
\end{array} \\
g & = & \text { acceleration due to gravity. } \\
\sigma_{v o} & = & \text { total overburden stress. } \\
\sigma_{v o}^{\prime} & = & \text { effective overburden stress. } \\
r_{d} & = & \text { stress reduction coefficient. }
\end{array}
$$

The $\mathrm{CRR}_{7.5}$ is a function of the CPTu data and is defined by Equations (3a) and (3b).

$$
\begin{gathered}
\text { If }\left(\mathrm{q}_{\mathrm{c} 1 N}\right)_{\mathrm{cs}}<50 C C R_{7.5}=0.833 \times\left[\frac{\left(q_{c 1 N}\right)_{C S}}{1000}\right]+0.05 \\
\text { If } 50 \leq\left(\mathrm{q}_{\mathrm{c} 1 \mathrm{~N}}\right)_{\mathrm{cs}}<160 C R R_{7.5}=93 \times\left[\frac{\left(q_{c 1 N}\right)_{c s}}{1000}\right]^{3}+0.08
\end{gathered}
$$

where:

$\left(q_{c I N}\right)_{c s}=$ clean-sand cone penetration resistance normalised to approximately $100 \mathrm{kPa}$.

The liquefaction potential is then calculated through Equation (4). 


$$
F S=\frac{C R R_{7.5}}{C S R} \times K \sigma \times M S F
$$

where:

$C S R$ and $C R R_{7.5} \quad$ are as defined above.

$K \sigma=$ overburden stress correlation factor.

$M S F \quad=\quad$ magnitude scaling factor.

\subsubsection{Post liquefaction strength}

The post liquefaction residual or steady state strengths are interpreted from CPTu data using the method outlined in Olson and Stark (2002). This method requires cone resistance in the assessment of shear strength rather than the cone resistance and local friction as is the case with the evaluation of extent of liquefaction.

\section{$4 \quad$ Case studies}

\subsection{Mine 1 - lead/zinc mine}

\subsubsection{General}

Mine 1 is a single point down valley thickened tailings discharge scheme, which has been in operation for a number of years. The beach is some $3.5 \mathrm{~km}$ in length and the rate of rise of the tailings is currently $1 \mathrm{~m}$ per year. Being a down-valley discharge scheme, a significant proportion of the tailings within the TSF are stored at an elevation higher than the tailings retaining embankment. Under these circumstances, there exists a perceived risk that seismic activity could cause liquefaction of the tailings resulting in flow slide failure. If failure of the tailings beach occurred it could, in the worst case, cause overtopping of the tailings retaining embankment and release of tailings into the downstream environment.

At the design stage, studies were carried out to assess this potential and the consequences of a liquefaction event. During this phase it was identified there was a risk of liquefaction flow slides during the initial six years of operation and thereafter there was likely to be liquefiable zones within the tailings, but that a flow slide was unlikely. Hence risk minimisation measures were built into the design during the initial operational years, i.e. a freeboard allowance was included to cater for potential seismic induced flow sliding of the tailings.

As part of the operating license for the TSF, liquefaction assessments were required in year two and year seven of operation. The year two investigation was carried out in 2002 and the results supported the analysis completed during the design stage.

The year seven investigation was carried out in 2008. The investigation consisted of the drilling of five boreholes with in situ testing and sample recovery and five CPTu probes with dissipation testing. In all cases the CPTu probing was completed prior to drilling an adjacent borehole.

The investigation locations were positioned at intervals down the beach. Two of the investigation locations were on sections of the beach that had been subjected to significant evaporative drying, one site was located in an area subject to less than one year of evaporative drying and two of the locations were in close proximity to the supernatant pond. The depth of the tailings deposit varies from approximately $5 \mathrm{~m}$ (upvalley) to in excess of $13 \mathrm{~m}$ adjacent to the supernatant pond.

The seismic loads considered for the study were an Operating Base Earthquke (OBE) of $0.06 \mathrm{~g}$ (1:500 year annual return interval (ARI)) and a Maximum Design Earthquake (MDE) of 0.21 g (1:10,000 year ARI). Seismic loads were determined by a site-specific seismic risk study.

The findings and results of the investigation are presented in Figures 3 to 7. 


\subsubsection{Subsurface conditions}

The general subsurface conditions revealed by the boreholes and CPTu traces in the tailings typically comprised varying thicknesses of tailings in the form of sandy silty clay and sandy clay; typically pale grey to dark grey/black in colour and generally in a firm state. The fines were found to be of low plasticity.

The tailings were found to exhibit some variation in grain size, density, and moisture over the tested profile. However, there was no apparent sorting or segregation of the tailings with distance from the deposition point.

The dry density of the beached tailings ranged from $1.54-1.81 \mathrm{t} / \mathrm{m}^{3}$. These dry densities were higher than the modelled consolidated densities and were generally at, or near the shrinkage limit density of $1.71 \mathrm{t} / \mathrm{m}^{3}$ determined through laboratory testing.

\subsubsection{Susceptibility to liquefaction}

The particle size distribution of the tailings recovered during the investigation is presented in Figure 3 . The data in Figure 3 shows the PSD is relatively well graded and that there is no distinct segregation apparent. This relatively well-graded particle size distribution on the beach is as expected for thickened tailings. Figure 3 indicates that on the basis of particle size the tailings can be considered to be susceptible to liquefaction.

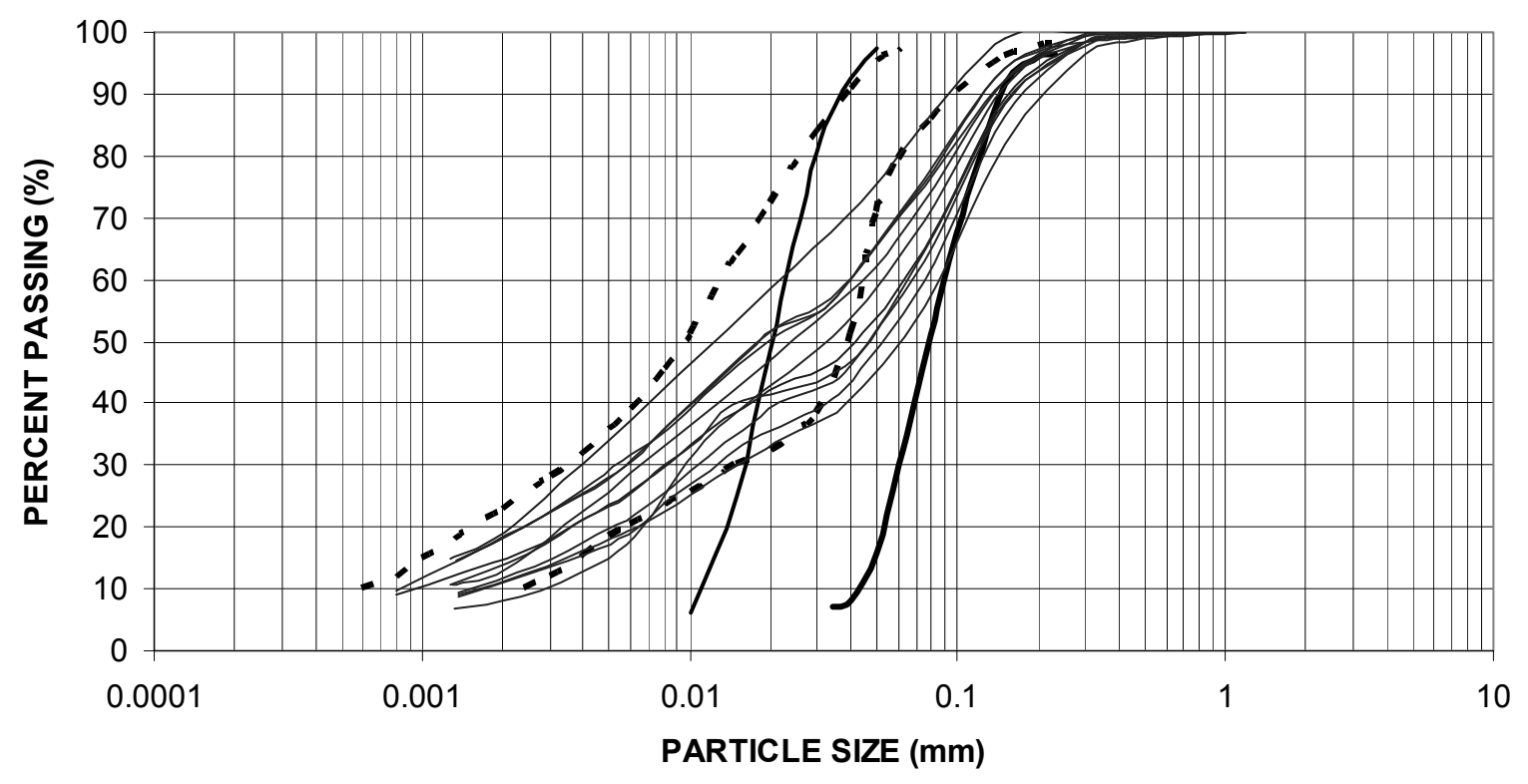

\section{Figure 3 Particle size distribution of tailings}

\subsubsection{Plasticity}

The plasticity of the tailings was compared to the Seed liquefaction criteria (Seed et al., 2003) and is presented in Figure 4. Figure 4 shows that the plasticity of the tailings falls within the zone of potentially liquefiable material provided the moisture content is $>0.8 \mathrm{x}$ Liquid Limit. The moisture content of the samples was generally within the range of 18.5 to $30.5 \%$ and the Liquid Limit was within the range 21 to 25 , indicating that the in situ state of the tailings is potentially liquefiable. 


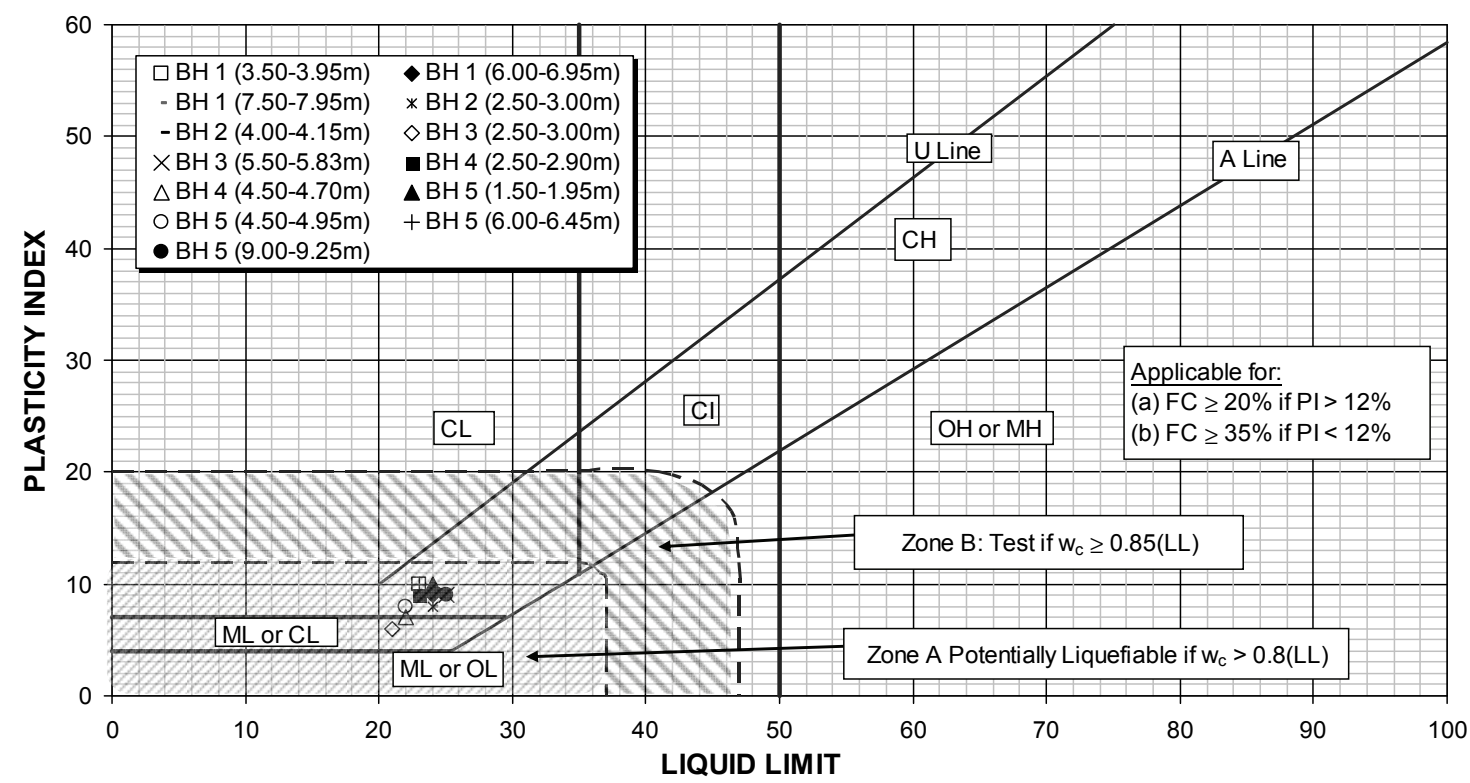

Figure 4 Tailings plasticity and susceptibility to liquefaction

\subsubsection{CPTu results and soil type and fines content}

The CPTu data was analysed using the Robertson (1990) method and the results were compared to the results of laboratory test results. The tailings were found, in the most part to be unsaturated to a depth of around $5 \mathrm{~m}$ at on-beach locations and became saturated through the entire profile adjacent to the supernatant pond. There was generally a good correlation between the apparent fines and the laboratory test results as shown in Figure 5. The test location presented in Figure was approximately $2 \mathrm{~km}$ upslope from the embankment. Figure 5 also indicates the tailings consist of sand and silt mixes which is in line with the results of particle size distribution tests presented in Figure 3. The laboratory test results of fines content indicate a relatively uniform tailings profile consistent with a non-segregating material.
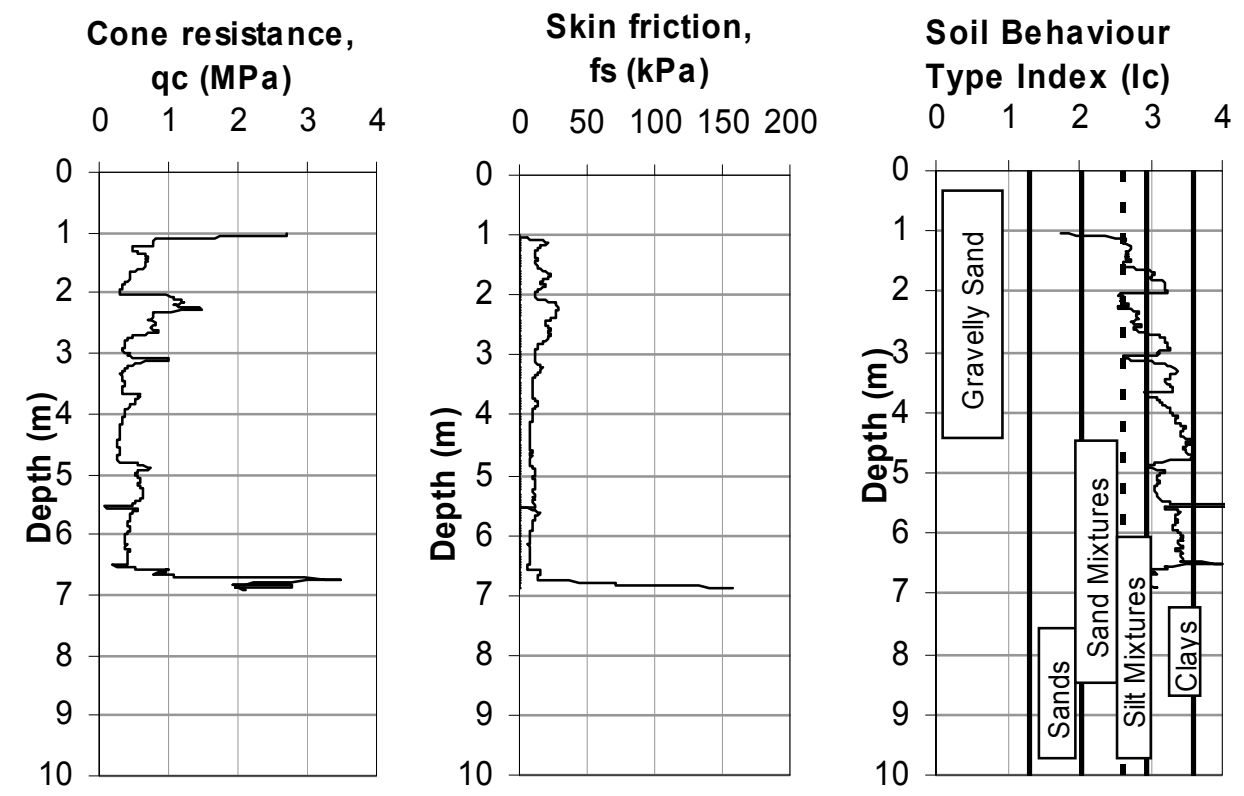

\section{Apparent Fines Content (FC) (\%)}

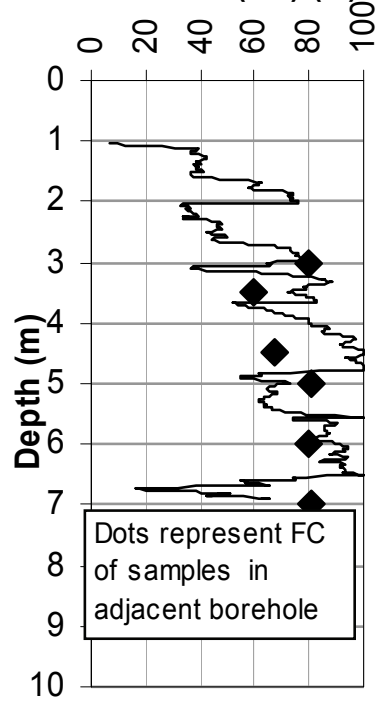

Figure 5 Comparison of apparent fines and laboratory test results for CPTu 1/BH 1 


\subsubsection{Interpreted strength}

The peak and residual undrained shear strength was determined using the Lunne et al. (2001) and Olson and Stark (2002) methods. The results are presented in Figure 6. These results were within the expected range for a this type of tailings and compared with shear strength ratios developed from triaxial test results during the design stage of 0.2 (peak) and 0.04 (residual).

It should be noted that peak shear strength ratio of 0.16 shown in Figure 6 is a conservative lower bound estimate and that the majority of the tailings had a higher peak shear strength ratio of about 0.21 . The majority of the tailings are above this lower bound estimate. Note that the strength scales differ on the two charts presented in Figure 6.
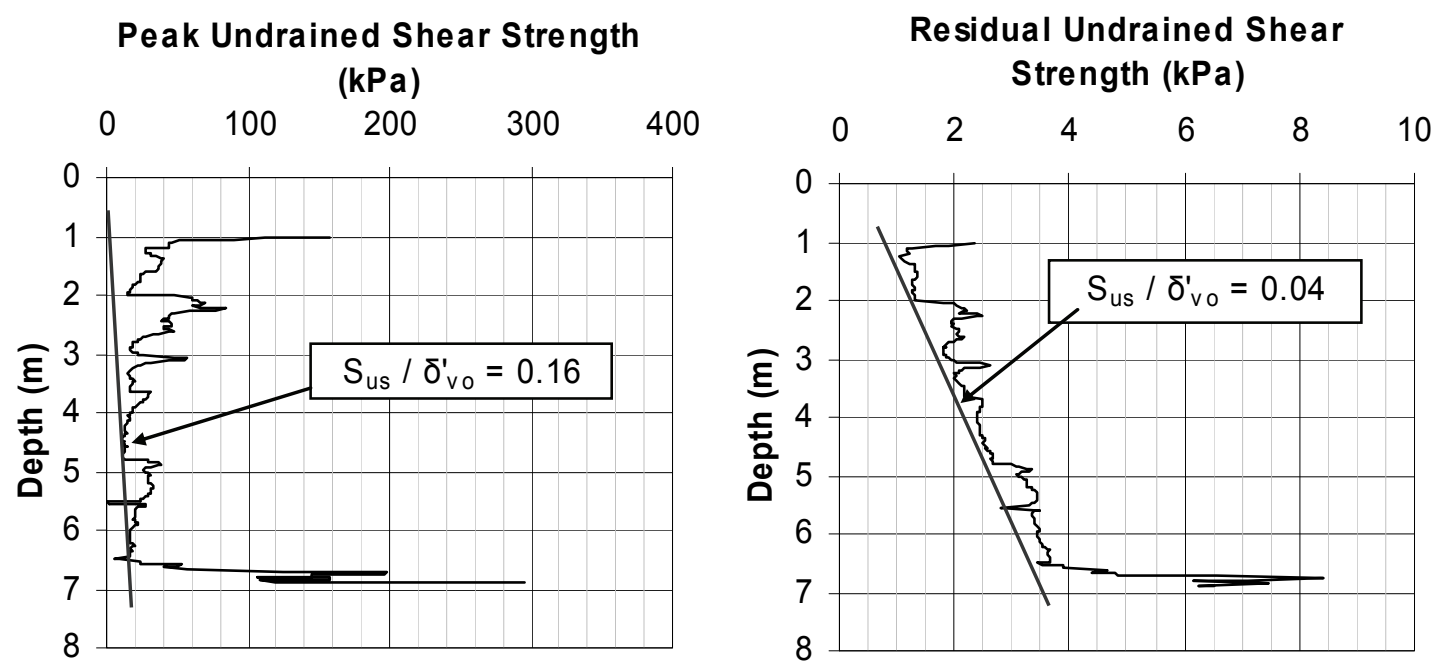

\section{Figure 6 Peak and residual shear strength for CPTu 1}

\subsubsection{Liquefaction assessment}

The liquefaction assessment was carried out in accordance with the Youd et al. (2001) method. The analysis (for the data presented) indicated that no liquefaction occurs under the OBE event, other than a point at a depth of about $5.6 \mathrm{~m}$ where the factor of safety is reported as zero. This is interpreted as an erroneous point in the CPTu data likely due to a rod change.

The results of the assessment for both the OBE and MDE seismic load cases are presented in Figure 7. Under the MDE seismic load the factor of safety is also greater than 1.0, although the margin is substantially reduced.

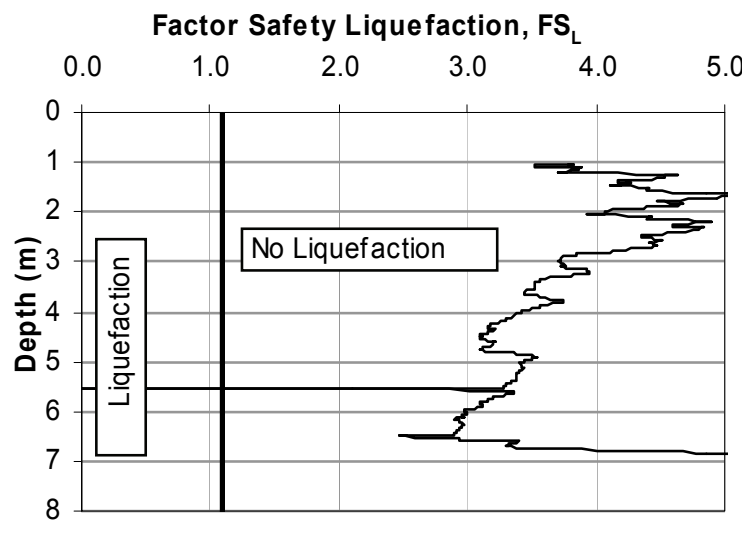

$\mathrm{FS}_{\mathrm{L}}$ under OBE load case

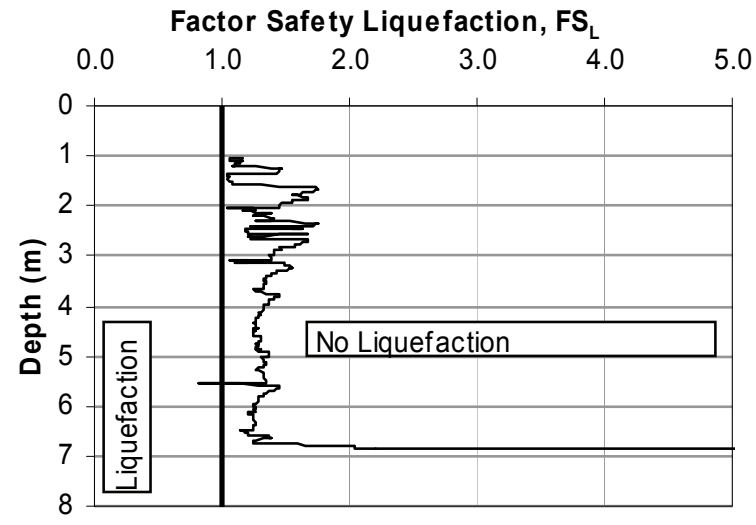

$\mathrm{FS}_{\mathrm{L}}$ under MDE load case

Figure 7 Factor of safety against liquefaction 


\subsubsection{Conclusions from assessment}

The CPTu data from the investigation indicated a relatively uniform tailings profile at all locations. The tailings were generally unsaturated to a depth of around $5 \mathrm{~m}$ at the on-beach locations and saturated through the entire profile adjacent to the supernatant pond.

The reassessment of liquefaction potential has shown that no liquefaction is predicted under the OBE and MDE seismic events and, although under the MDE seismic load the factor of safety margin is substantially reduced.

The original analysis predicted that from about year 7.2 onwards that there would be some liquefiable layers present within the profile.

On this basis the liquefaction potential of the tailings is considered to be in line with predictions.

\subsection{Mine 2 - gold mine}

\subsubsection{General}

Mine 2 disposes tailings by discharging from a perimeter embankment with a central decant. The rate of rise of the tailings is currently $2 \mathrm{~m}$ per year.

The tailings discharged have a solids content of 20 to $30 \%$ which is segregating, and operationally has had high decant pond levels with water ponded close to the embankments.

A starter embankment has been followed by several raises which are a combination of centre line and upstream raises. As construction in part is over the deposited tailings, the strength and density of the tailings under static and seismic loading is critical to the stability of the embankment.

The main investigation for the raised sections of the embankment consisted of the drilling of 11 boreholes and 15 hand auger holes with in situ testing and sample recovery and monitoring bore installation. In addition, $17 \mathrm{CPTu}$ probes with dissipation testing were undertaken.

The seismic loads considered for the study were for an OBE of 1:500 year ARI with a peak ground acceleration of $0.13 \mathrm{~g}$ and an MDE of 1:5,000 year ARI with a peak ground acceleration of $0.36 \mathrm{~g}$. The findings and results of the investigation are presented in Figures 8 to 11.

\subsubsection{Subsurface conditions}

The general subsurface conditions revealed by the boreholes and CPTu traces in the tailings typically comprised varying thicknesses of sandy silt, silty sand, sand and silts/clays generally in a very soft to soft state. The fines were found to be of low plasticity. The tailings at the discharge are sandy silt.

The tailings were found to vary in grain size, density, and moisture with depth and distance from the existing embankment. Tailings were generally found to be coarser grained closer to the discharge location (existing embankment) and becoming more fine grained away from the discharge locations as expected with a segregating tailings.

Generally the tailings were found to have a higher phreatic surface at shallower depths and the further the borehole was located from the embankments the higher the phreatic surface. For the data presented, the general water level was about $0.5 \mathrm{~m}$ higher for the borehole $15 \mathrm{~m}$ closer to the decant and the overall depth to water below the head of beach was in the order of $5 \mathrm{~m}$.

\subsubsection{Shear strength (shear vane)}

The shear strength of the tailings showed a tendency to decrease with distance from the discharge points (embankment crest) coinciding with the hydraulic sorting of the tailings. Typically lower shear strengths were experienced in the fine (silty) layers and higher shear strengths in the sands and silty sands. The results of the peak shear strength ranged from as little as $1 \mathrm{kPa}$ up to $240 \mathrm{kPa}$ and the residual shear strength in the range $1 \mathrm{kPa}$ up to $100 \mathrm{kPa}$. 


\subsubsection{Density}

The results of near surface field tests for dry density of the beached tailings ranged from $1.23-1.44 \mathrm{t} / \mathrm{m}^{3}$ and the overall density of the storage facility was estimated to be $1.1 \mathrm{t} / \mathrm{m}^{3}$. By comparison, laboratory testing of samples recovered during the investigation indicated a maximum density in the order of $1.85 \mathrm{t} / \mathrm{m}^{3}$ and the minimum density of $1.15 \mathrm{t} / \mathrm{m}^{3}$.

\subsubsection{CPTu results and soil type}

Four CPTu tests were carried out down the beach at site 1 (the data presented), with CPT 1A being closest to the decant and CPT 1D being closest to the embankment. The results of the CPTu tests at this site are presented in Figure 8 (note that the strength scales differ between $q_{c}$ and $f_{s}$ ). The CPTu data was analysed using the Robertson (1990) method and compared to the results of laboratory test results. There was generally a good correlation between the apparent fines and the laboratory test results as shown in Figure 8 . The results show that the tailings are generally finer further from the embankment.
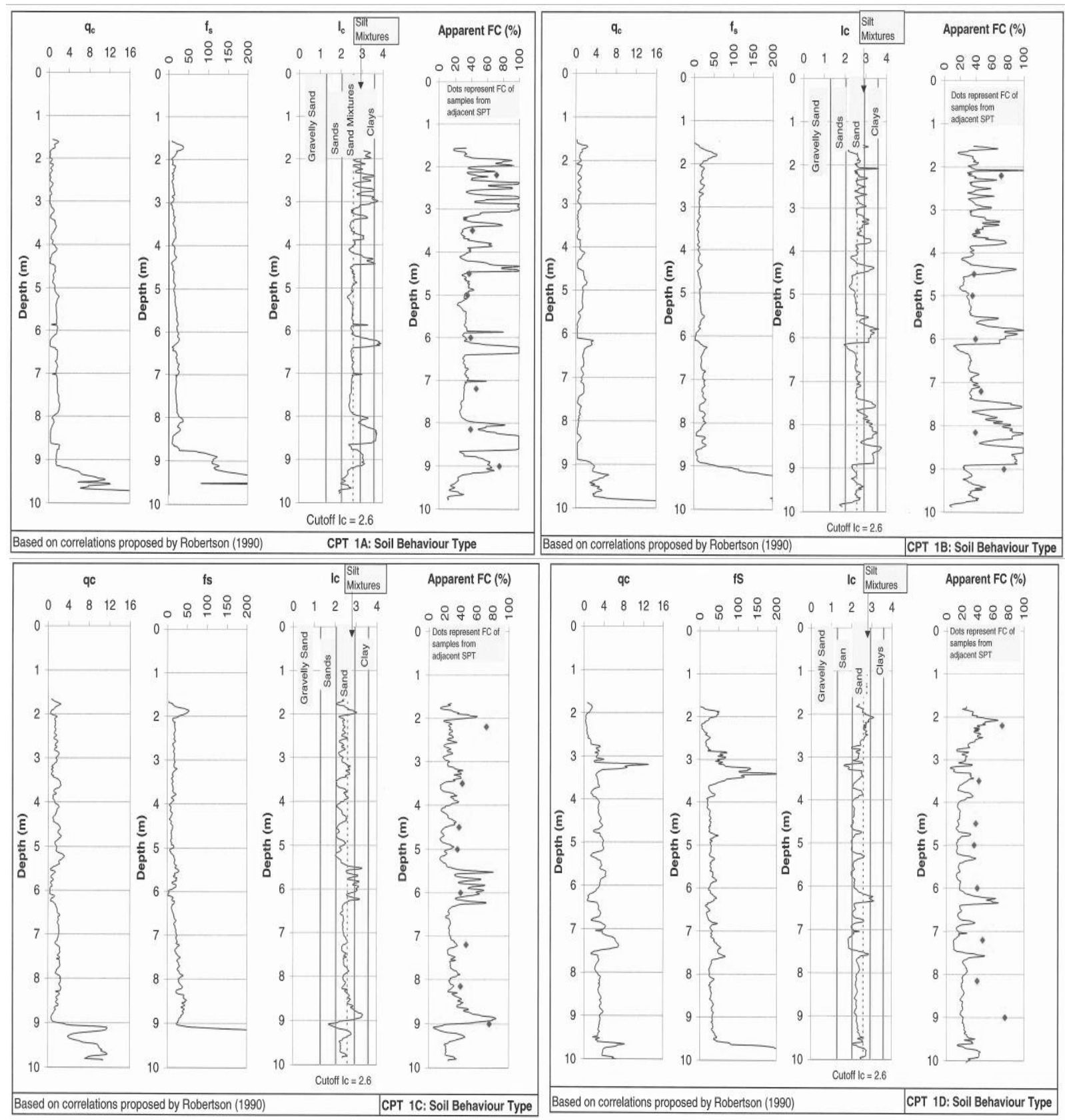

Figure 8 Comparison of apparent fines and laboratory test results for CPTu 1/BH 1A, 1B and 1C 


\subsubsection{Interpreted strength}

The peak and residual undrained shear strength was determined using the Lunne et al. (2001) method. The results are presented in Figure 9. For the peak strength the silts and sands were separated and the lower bound undrained strength adopted for each. The tailings are generally stronger closer to the embankment as is seen by the results for CPT 1D compared to CPT 1A. The tailings also increase in strength with an increase in depth as would be expected with hydrostatic consolidation. The exception to this being the very low strengths at around $6 \mathrm{~m}$. Lower strength was also recorded at $8 \mathrm{~m}$ in the two CPT tests (CPT 1A and CPT 1B) furthest from the embankment. Some excess pore pressure was noted during the pore pressure dissipation testing at these levels. From this we conclude that the tailings at these locations are probably under-consolidated. These low strengths also relate to generally higher fines content. It is expected that the reason for these variations is operational with a larger pond area at the time of deposition or fines being allowed to deposit in these areas.
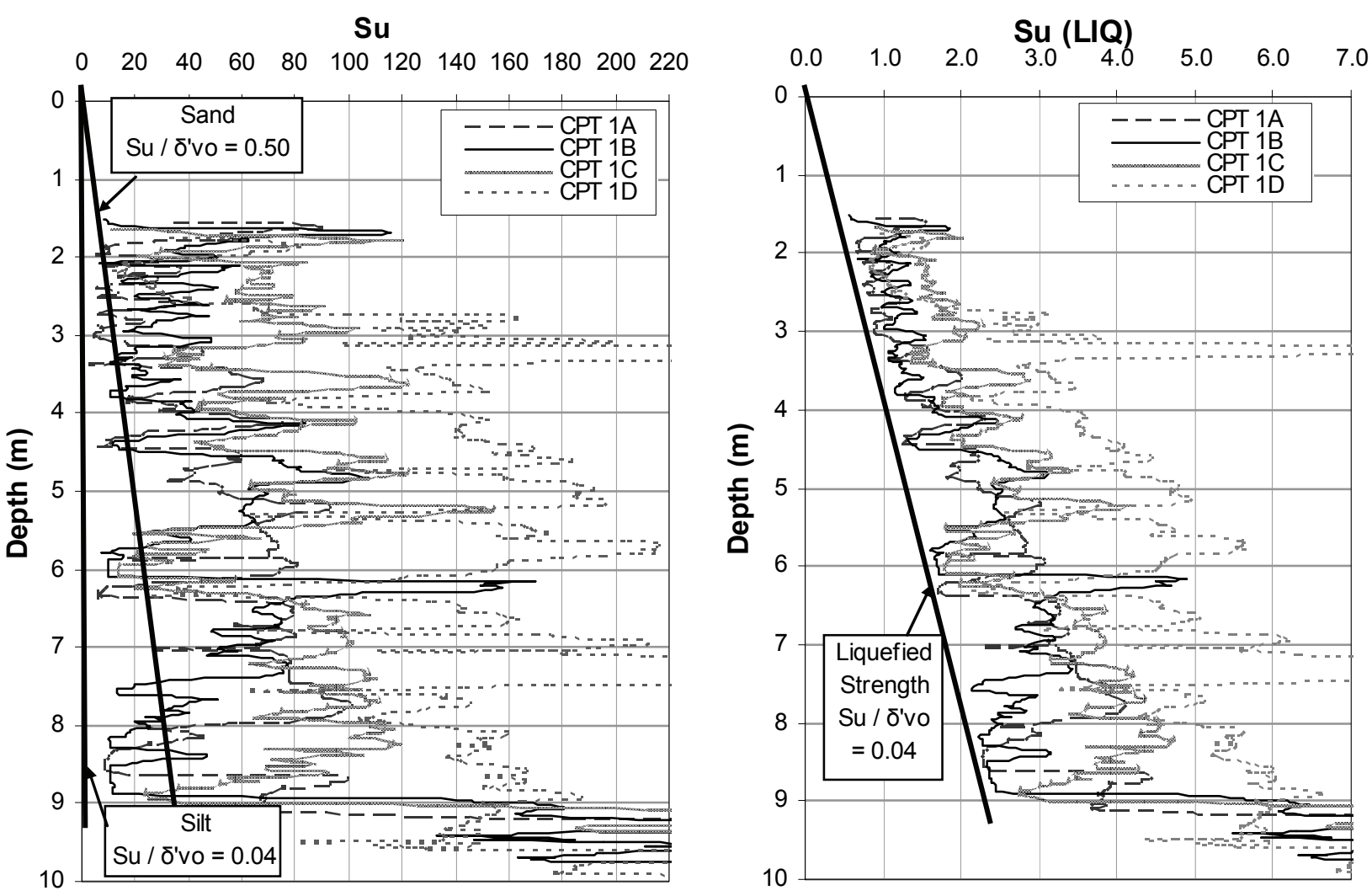

Figure 9 Peak and residual shear strength for CPTu 1A, 1B, 1C and 1D

\subsubsection{Plasticity}

The plasticity of the tailings was compared to the Seed liquefaction criteria (Seed et al., 2003) and results are presented in Figure 10. This shows that the plasticity of the tailings falls within the zone of potentially liquefiable material provided the moisture content is $>0.8 \times$ Liquid Limit. The moisture content of the samples was generally above the liquid limit, indicating that the in situ state of the tailings can be considered is potentially liquefiable on the grounds of plasticity. 


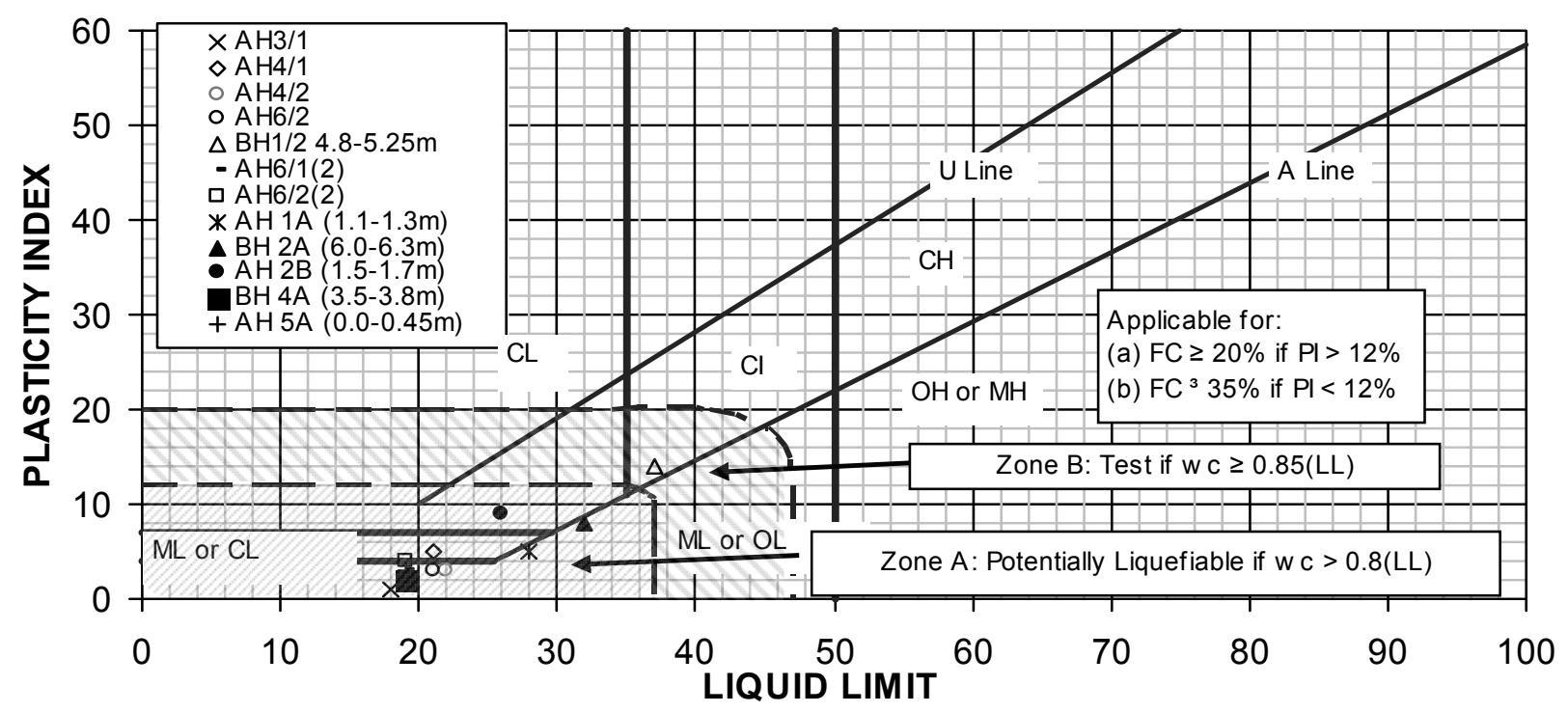

Figure 10 Tailings plasticity and susceptibility to liquefaction

\subsubsection{Liquefaction assessment}

The liquefaction assessment was carried out in accordance with the Youd et al. (2001) method. The analysis indicated that there is potential for liquefaction under the OBE and MDE event.

The results of the assessment for the OBE seismic load case for Site 1 are presented in Figure 11. This shows that the tailings are potentially liquefiable.
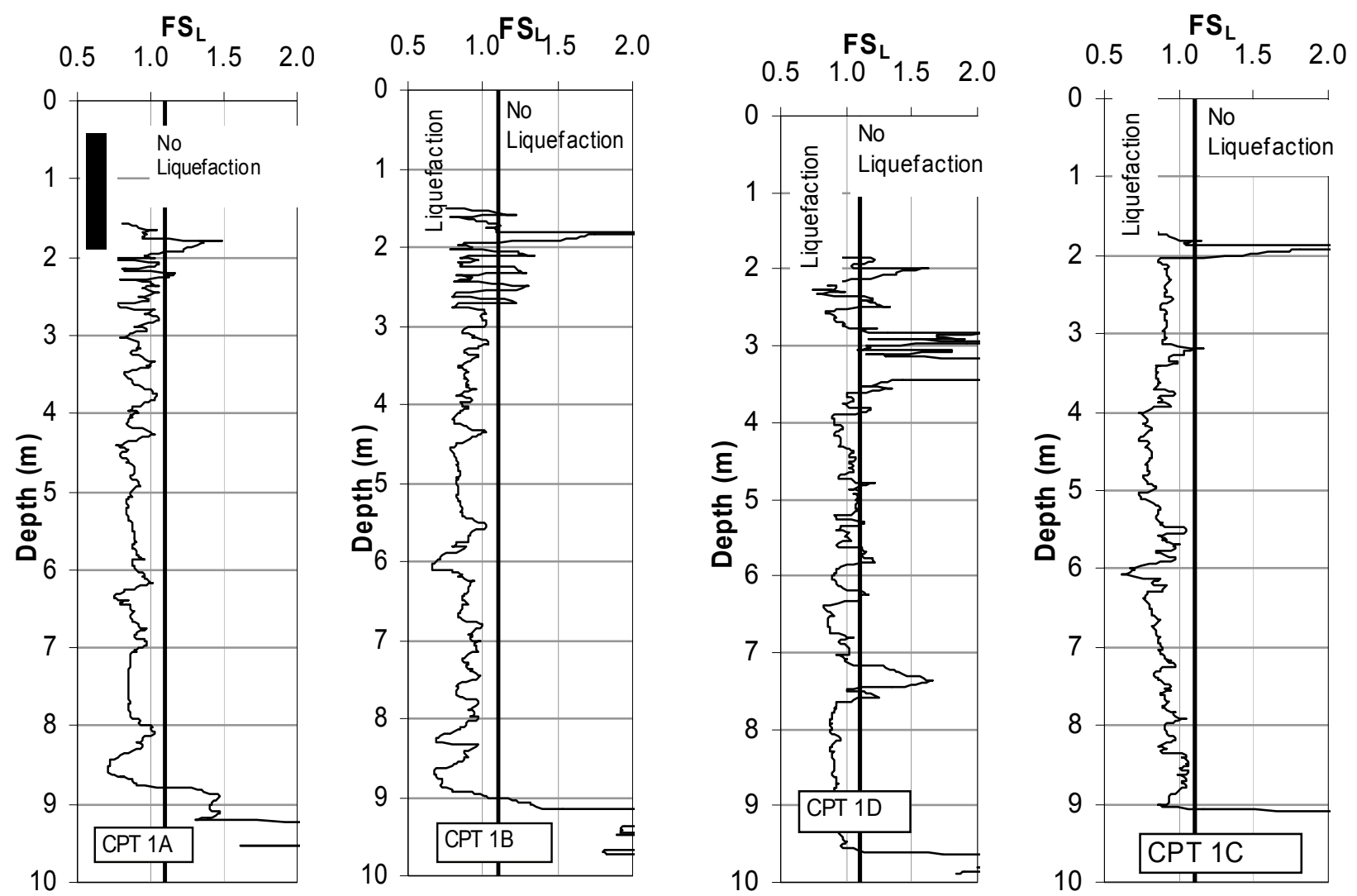

Figure 11 Factor of safety against liquefaction for OBE load case 


\subsubsection{Conclusions from assessment}

The assessment of liquefaction potential has shown that the potential for liquefaction is predicted under the OBE and MDE seismic events. As the tailings are found to be saturated at least in part on the basis of the phreatic surfaces measured in the monitoring bores the liquefied strengths were considered during design.

\subsection{Comparison of results}

A comparison of the results from the two investigations indicates:

- The seismic coefficients were higher for Mine 2 than Mine 1.

- The tailings from Mine 1 were finer than those from Mine 2.

- The plasticity of the two materials was similar.

- The density of the Mine 1 tailings was somewhat higher than those at Mine 2.

- The peak shear strength ratio of Mine 1 is lower than that of Mine 2 but the residual shear strength ratios were similar.

- The tailings at Mine 1 were relatively uniform whereas the tailings at Mine 2 were variable and indicated a layered sandy and silty profile.

- The Mine 1, down valley thickened tailings were generally unsaturated to a depth of around $5 \mathrm{~m}$ for 'on-beach' sites, becoming saturated through the entire profile adjacent to the supernatant pond whilst the perimeter spigot discharge tailings at Mine 2 were saturated in the case of site 1 at a depth of about $5 \mathrm{~m}$ below the head of beach.

- Mine 1 tailings were not susceptible to liquefaction where as Mine 2 tailings were.

\section{Conclusions}

The main difference between the two mine tailings are the density and degree of consolidation of the tailings as well as the seismic coefficients adopted, resulting in Mine 2 being more susceptible to liquefaction than Mine 1. Mine 2 tailings were deposited at a lower, and remained at a lower density than Mine 1 tailings and the Mine 2 tailings had some excess pore pressure in the tailings.

It can be concluded that a down valley thickened discharge regime leads to a more well graded and more dense tailings stack, has a lower, more reliable phreatic surface and hence the susceptibility to liquefaction of the deposited tailings is lower.

\section{References}

Ishihara, K., Troncoso, J.H., Kaware, Y. and Takahashi, Y. (1980) Cyclic Strength Characteristics of Tailings Materials, Soils and Foundations, Vol. 20, No. 4.

Lunne, T., Robertson, P.K. and Powell, J.J.M. (2001) Cone Penetration Testing in Geotechnical Practice, Blackie Academix and Professional, pp. 63-66.

Olson, S. and Stark, T. (2002) Liquefied Strength Ratio from Liquefaction Flow Failure Case Histories, Canadian Geotechnical Journal, Vol. 39, pp. 627-647.

Robertson, P.K. (1990) Soil Classification using the Cone Penetration Test, Canadian Geotechnical Journal, Vol. 27.

Seed, R.B., Cetin, K.O., Moss, R.E.S., Kammerer, A.M., Wu, J., Pestana, J.M., Riemer, M.F., Sancio, J.B., Bray, J.D., Kayen, R.E. and Faris, A. (2003) Recent Advances in Soil Liquefaction Engineering: A Unified and Consistent Framework, 26th Annual ASCE Los Angeles Geotechnical Spring Seminar.

Youd, T.L., Idriss, I.M., Andrus, R.D., Arango, I., Castro, G., Christian, J.T., Dobry, R., Finn, W.D., Harder Jr., L.F., Hynes, M.E., Ishihara, K., Koester, J.P., Liao, S.S.C., Marcuson III, W.F., Martin, G.R., Mitchell, J.K., Moriwaki, Y., Power, M.S., Robertson, P.K., Seed, R.B. and Stofoe II, K.H. (2001) Liquefaction Resistance of Soils: Summary Report from the 1996 NCEER and 1998 NCEER/NSF Workshops on Evaluation of Liquefaction Resistance of Soils, Journal of Geotechnical and Geoenvironmental Engineering, October, pp. 817-833. 